\title{
Manejo clínico das disfunções orais na amamentação
}

\author{
Clinical management of oral disorders in breastfeeding
}

\author{
Maria Teresa C. Sanches*
}

\section{Resumo}

Objetivo: Abordar os aspectos relacionados com a detecção precoce e o manejo clínico das disfunções orais na amamentação.

Fontes de dados: Revisão bibliográfica com enfoque no manejo clínico das disfunções orais em crianças amamentadas, utilizando artigos científicos, livros técnicos, teses e publicações nacionais e internacionais.

Síntese dos dados: As disfunções orais (desordens da sucção do bebê), se não corrigidas precocemente, podem gerar ações inadequadas, prejudicando o desempenho satisfatório entre mãe e bebê na mamada. Os profissionais de saúde podem contribuir nesses casos, reconhecendo e intervindo precocemente através de capacitação para a avaliação da mamada e para o manejo clínico adequado das disfunções orais. No manejo clínico para bebês com dificuldades na amamentação, devem ser considerados os aspectos relevantes da fisiologia oral e observação da amamentação para essa prática. Destaca-se a importância do trabalho de uma equipe interdisciplinar e das precauções necessárias quanto ao treino oral desses bebês, bem como a necessidade de acompanhamento por especialista treinado nos casos mais complexos.

Conclusão: As disfunções orais do bebê na amamentação podem ser corrigidas, desde que identificadas precocemente. Os profissionais de saúde podem auxiliar mães e bebês a superar essa dificuldade, capacitando-se para realizar uma prática clínica adequada na amamentação.

J Pediatr (Rio J). 2004;80(5 Supl):S155-S162: Amamentação, recém-nascido, comportamento de sucção.

\section{Introdução}

Recém-nascidos (RN) e lactentes saudáveis, sem intercorrências que interfiram na amamentação, ocasionalmente apresentam movimentos orais atípicos (disfunções orais) durante a mamada, os quais podem causar dificuldades na amamentação decorrentes de alterações

* Mestre e doutoranda em Saúde Pública, Faculdade de Saúde Pública, Universidade de São Paulo (USP). Fonoaudióloga e pesquisadora integrante do Instituto de Saúde, Secretaria de Estado da Saúde de São Paulo. Aperfeiçoamento e Conselheira em Amamentação.

Como citar este artigo: Sanches MTC. Manejo clínico das disfunções orais na amamentação. J Pediatr (Rio J). 2004;80(5 Supl):S155-S162.

\begin{abstract}
Objective: To address aspects associated with the early detection and clinical management of oral disorders in breastfeeding.

Source of data: Review of bibliographic sources (research articles, technical books, dissertations and national and international publications) focused on the clinical management of oral disorders in breastfed babies.
\end{abstract}

Summary of the findings: Suction disorders may lead to inadequate actions that can compromise the mother/baby relation during breastfeeding. Healthcare professionals may have an important role in these cases, as they can early detect such disorders. For that end, they must be able to assess breastfeeding and be prepared to manage oral disorders clinically. In the clinical management of babies with breastfeeding difficulties significant aspects of the oral physiology and breastfeeding observation should be considered. We stress the importance of an interdisciplinary team work and the need for oral training and specialized care in most complex cases.

Conclusion: The baby's oral disorders in breastfeeding can be corrected if they were early detected. Healthcare professionals may help mothers and babies to overcome these problems if they have knowledge that enable them to perform right clinical procedures.

J Pediatr (Rio J). 2004;80(5 Supl):S155-S162: Breastfeeding, newborn, suction behavior.

transitórias do próprio funcionamento oral, ou mesmo de algumas características individuais anatômicas que dificultam o encaixe adequado entre a boca do bebê e a mama de sua mãe, ou, ainda, de fatores iatrogênicos. As disfunções orais encontram-se entre os vários fatores interferentes para o estabelecimento do aleitamento materno relacionados ao bebê e podem gerar traumas mamilares, pouco ganho de peso do bebê e até desmame precoce $^{1-4}$.

Embora as disfunções orais sejam passíveis de serem revertidas precocemente, as ações entre mãe/bebê nas primeiras mamadas rapidamente se tornam hábitos bem estabelecidos, difíceis de mudar, principalmente em relação 
ao padrão de sucção do RN. Por esse motivo, a avaliação detalhada da mamada e ações específicas para a correção de alterações são muito importantes logo no início da amamentação ${ }^{2,5}$.

A seguir são abordados aspectos da fisiologia da amamentação e avaliação da mamada, destacando-se aspectos do funcionamento oral e identificação de resoluções das principais disfunções orais, com o intuito de contribuir para o diagnóstico e a prática dos profissionais de saúde no manejo clínico dessas alterações orais.

\section{Fisiologia da sucção (ordenha) na amamentação}

Desde o período embrionário, o feto prepara-se para exercer as atividades de sugar, deglutir, respirar e chorar, que irão possibilitar sua sobrevivência ao nascer. Para tanto, é munido dos reflexos orais, que garantem sua alimentação nessa fase inicial do desenvolvimento, e apresenta características anatômicas diferenciadas, que facilitarão a alimentação no período neonatal ${ }^{6,7}$.

Devido ao pequeno crescimento mandibular no período neonatal (retração mandibular fisiológica), a língua se apóia sobre a gengiva ou lábio inferior, numa posição anteriorizada e rebaixada, ocasionando um espaço aéreo-faríngeo que obriga à respiração nasal, a qual ocorre em todo RN. O volume aumentado da língua, maior que a estrutura óssea que a suporta (mandíbula), está ligado à sua função na alimentação, já que o contato com o lábio inferior permite uma postura adequada para a amamentação6,8. Na parte posterior da boca, a base da língua encontra-se bem próxima à epiglote, em razão do posicionamento mais alto que a laringe do RN ocupa (bem próximo ao palato mole) até o terceiro ou quarto mês, com função de proteção das vias aéreas inferiores durante a deglutição, facilitando também o acesso do alimento ${ }^{9}$. Essas diferenças anatômicas do RN são importantes porque o sistema oral infantil ainda não está tão estruturado e eficiente quanto no adulto para coordenar sucção, deglutição e respiração.

As estruturas anatômicas importantes para o funcionamento oral do RN incluem cavidade oral, lábios, língua, bochechas, mandíbula, palato duro e mole, osso hióide, cartilagem tireóide, epiglote, musculaturas facial e perioral e músculos constritores da faringe, além de outros 40 músculos que envolvem a movimentação de todo o sistema oral. Os pares dos nervos cranianos responsáveis pela inervação dessa musculatura são: I - olfativo; V - trigêmeo; VII - facial; IX - glossofaríngeo; X - vago; e XII hipoglosso 6,10 .

Os reflexos orais do RN garantem sua alimentação nessa fase inicial do desenvolvimento e são os seguintes: busca ou procura (ativado mediante toque na bochecha e, principalmente, nos quatro pontos cardeais dos lábios), cuja função consiste em localizar o peito; sucção (desencadeado pelo toque na ponta da língua e papila palatina), sendo sua função a retirada do leite; e deglutição (obtido mediante estímulo do leite na região posterior da língua, palato mole, faringe e epiglote). Há, ainda, os seguintes reflexos de proteção da deglutição: mordida (obtido mediante o toque na região interna das gengivas), vômito (desencadeado pelo estímulo na ponta da língua quando há negação total da deglutição) e tosse ${ }^{7}$. Após o quarto ou quinto mês, com o crescimento das estruturas orais, o amadurecimento do sistema nervoso e as possibilidades de experimentação oral adequada da criança, essa condição basicamente reflexa vai se modificando, sendo substituída por um padrão voluntário de movimentação oral ${ }^{8}$.

Apesar de a sucção ser um ato reflexo, a ordenha, ou seja, a extração do leite do peito não é, o que exige do bebê aprender a retirar o leite, adaptando suas condições orais anatômicas para o encaixe na mama de sua mãe (pega); nem sempre esse encaixe é fácil, e podem ocorrer algumas dificuldades no decorrer do processo $5,11,12$. Bu'Lock et al. ${ }^{13}$ salientam a importância da pega correta na amamentação, tendo como base estudos que utilizaram cinerradiografias, datados a partir de 1950, e confirmados posteriormente com estudos de imagens ultrasonográficas, a partir da década de $1980^{14}$, possibilitando a compreensão dos movimentos da língua dentro da boca do bebê.

Na pega correta, o bebê realiza uma abertura ampla da boca, abocanhando não apenas o mamilo, mas também parte da aréola, e formando um lacre perfeito entre as estruturas orais e a mama. Para a formação desse lacre, na parte anterior os lábios estão virados para fora, (sendo que o lábio superior e a língua são os principais responsáveis por um vedamento adequado), e a língua se apóia na gengiva inferior, curvando-se para cima (canolamento), em contato com a mama. A finalidade do lacre consiste na formação do vácuo intra-oral (com a presença de pressão negativa), formado por movimentos da mandíbula associados a movimentos dos lábios, bochechas e coxins de gordura. Os coxins de gordura ou sucking pads são bolsões de gordura localizados entre a pele e a musculatura das bochechas, com a finalidade de auxiliar na sustentação das estruturas orais para o acoplamento perfeito ao peito.

A mandíbula se apóia sobre os seios lactíferos (onde o leite fica armazenado), e o bebê abocanha o mamilo e aproximadamente 2 a $3 \mathrm{~cm}$ de aréola. Na parte posterior da boca, a língua se eleva e funciona como um mecanismo oclusivo contra o palato mole, estabelecendo, assim, a pressão intra-oral negativa (juntamente com o vedamento anterior). Essa pressão mantém a mama (mamilo + aréola) dentro da boca do bebê, apesar de sua natureza retrátil. Desta forma, o mamilo e parte da aréola são deslocados para o interior da boca, sendo que o bico do peito toca a região de transição entre o palato duro e o palato mole, facilitando a extração do leite e a deglutição. A mandíbula realiza um ciclo de movimentos, iniciando com o abaixamento para a abertura da boca (com a participação dos músculos abaixadores da mandíbula, supra- e infra-hióideos, miloióideo, genoióideo e digástrico). Posteriormente, ocorre a protrusão (anteriorização) mandibular, que tem por objetivo alcançar a mama, principalmente os seios lactíferos (com ação dos músculos pterigóideos mediais, masseter e pterigóideos laterais). Prosseguindo, a mandíbula realiza uma elevação 
para imprimir o fechamento da boca e a compressão dos seios lactíferos (músculos masseter, pterigóideo medial e temporal) e, em seguida, o movimento de retrusão (posteriorização) para a extração efetiva do leite (ação das fibras oblíquas e horizontais dos músculos temporal e digástrico e das fibras superiores do músculo pterigóideo lateral). Esses movimentos mandibulares trazem estímulos importantes para o crescimento da articulação têmporo-mandibular e, conseqüentemente, para o crescimento harmônico da face do bebê ${ }^{8,14-17}$.

Durante a amamentação, a língua eleva suas bordas lateralmente (musculaturas transversal e vertical), juntamente com a ponta, formando uma concha, que levará o leite para ser deglutido na orofaringe ${ }^{14-16}$. Quando o leite se deposita sobre a língua, na região posterior da boca, entra em ação um movimento peristáltico rítmico, direcionando-se da ponta da língua para a orofaringe, que comprime suavemente o mamilo por inteiro e termina o processo de extração de leite para início da deglutição. A ponta da língua se mantém na região anterior durante todo o processo, garantindo o vedamento da boca. Desta forma, o leite é extraído suavemente, sem a utilização de mecanismos de força, o que poderia causar atrito e esfolamento dos mamilos ${ }^{14-17}$.

\section{Avaliação da mamada}

Considerando-se que rotinas hospitalares e práticas de profissionais de saúde podem facilitar o estabelecimento e a duração do aleitamento materno, a Organização Mundial de Saúde (OMS) e o Fundo das Nações Unidas para a Infância (UNICEF) centram esforços para a instituição de uma política pública de incentivo à amamentação desde a década de 80. Em 1991, foi lançada a Iniciativa Hospital Amigo da Criança (IHAC), a qual propõe modificações nas rotinas das maternidades para atender os Dez passos para o sucesso do aleitamento materno ${ }^{18-21}$. Um desses passos - o de número 2 - sugere que todos os profissionais da equipe que prestam assistência às mães e aos bebês sejam treinados adequadamente no manejo clínico da amamentação. Esse treinamento é feito por meio de cursos que enfatizam a avaliação da mamada por meio de protocolo específico (formulário de observação e avaliação da mamada), com observação da postura corporal da mãe/bebê, respostas do bebê (comportamento global), vínculo emocional entre mãe/bebê, anatomia da mama, aspectos da sucção e funcionamento oral. O objetivo primordial do treinamento da avaliação da mamada é o de identificar problemas no início da amamentação e verificar qual grupo de mães/RN apresenta necessidades especiais e requer apoio para um início bem-sucedido 21,22.

Na avaliação da mamada, é importante observar dois pontos-chave: posicionamento e pega. A posição inadequada da mãe e/ou do bebê na amamentação dificulta o posicionamento correto da boca do bebê em relação ao complexo aréolo-mamilar, resultando no que se denomina de má pega. Esta, por sua vez, interfere na dinâmica de sucção e extração de leite, podendo gerar traumas mamilares, dor e desconforto para a mãe, dificultando inclusive a continuidade do aleitamento, caso não seja devidamente corrigida11,12,18,23-26.

Independentemente da posição que a mãe e seu filho assumam na amamentação, é imprescindível que ambos se sintam confortáveis e que a mãe possa facilitar os reflexos orais do bebê, ajudando-o a abocanhar uma porção adequada da mama (pega ótima). Assim, e com o bebê bem apoiado, ele pode remover o leite efetivamente, deglutir e respirar livremente. Durante a ordenha do peito, é importante que os RN, que estão em fase de aprendizagem, fiquem com seu corpo sempre voltado para o corpo da mãe e próximos do mesmo, com sustentação do quadril, de forma que a boca permaneça na altura do mamilo e da aréola. O posicionamento inadequado pode tornar a mamada ineficiente, dificultando a transferência do leite posterior (do final da mamada), mais rico em energia. Como conseqüência, pode haver desconforto da mãe e esforço excessivo do bebê, fazendo com que ele se canse rápido e adormeça ou permaneça agitado, com fome, querendo mamar com muita freqüência, demonstrando-se irritado e choroso. Esse quadro pode culminar com o bebê "brigando" com a mama, ou mesmo recusando o peito, interferindo negativamente no seu ganho de peso, vindo a reforçar a idéia errônea da mãe e de familiares de que o leite é insuficiente ou fraco e gerando conflitos, frustração e dúvidas na mãe quanto à sua capacidade de alimentar o bebê $\hat{e}^{5,11,12,18,25,27,28}$.

Em relação à pega e à ordenha do bebê, é importante observar como se desencadeiam os reflexos orais, se o bebê demonstra sinais de fome e procura e se está alerta e organizado para a mamada. Quanto à pega, é importante verificar se o queixo toca a mama, se os lábios estão voltados para fora, realizando um correto selamento labial, e se uma área maior de aréola é visível acima, e não abaixo, da boca do bebê. Deve-se observar também se a língua envolve inferiormente o complexo aréolo-mamilar durante a sucção. Os movimentos de ordenha da mandíbula devem ser suaves, coordenados com o ritmo de deglutição e respiração, sem a participação do músculo bucinador (ausência de covinhas), e as sucções devem ser lentas e profundas, com pausas $5,11,12,25$.

É importante também que os profissionais de saúde estejam atentos para as condições gerais das mamas e mamilos, observando ingurgitamento e traumas mamilares, situações que dificultam sobremaneira a amamentação 18,28 . Também é importante observar vínculo entre mãe e filho pela forma de segurar o bebê, toques físicos durante a mamada e contato visual. Numa avaliação efetiva da mamada, deve-se observar a dupla antes, durante e depois da mamada, com o objetivo de conferir o grau de satisfação do bebê e de conforto (ausência de dor) da mãe 12,18,22,27.

O período puerperal é um momento delicado, uma vez que requer aprendizagem e observação da mãe para compreender e satisfazer às necessidades do seu bebê, bem como habilidades deste para demonstrar suas preferências, comportamento e até dificuldades ${ }^{29}$. Desta forma, exige atenção e cuidados especiais da equipe de 
saúde, bem como uma avaliação mais criteriosa da amamentação $12,22,27,30$.

Alguns estudos têm demonstrado aspectos críticos relacionados às dificuldades iniciais no estabelecimento da amamentação. Carvalhaes \& Correa ${ }^{22}$ aplicaram a 50 duplas de mães/RN o protocolo sugerido pelo UNICEF ${ }^{18}$ (Formulário de observação e avaliação da mamada) em uma maternidade de Botucatu (SP). As autoras observaram que 18 a 34\% das duplas mães/bebês apresentaram alguma dificuldade com o início da amamentação em uma das áreas avaliadas: postura corporal da mãe/bebê, respostas do bebê (comportamento global), vínculo emocional entre mãe/bebê, anatomia da mama e aspectos da sucção e funcionamento oral. Essas dificuldades foram mais freqüentes quando as mães foram submetidas à cesariana e quando eram oferecidos suplementos aos neonatos.

Sanches ${ }^{27}$ realizou um estudo fonoaudiológico de observação da mamada em 409 binômios mães/RN a termo, saudáveis, na maternidade do Hospital Guilherme Álvaro, em Santos (SP), credenciado como Hospital Amigo da Criança (UNICEF/1993). Com o objetivo de estudar fatores associados às dificuldades iniciais da amamentação, o autor identificou $13 \%$ de dificuldades iniciais na mamada, apesar de tratar-se de uma população com condições orgânicas, psíquicas e funcionais favoráveis para a amamentação. Entre diversas variáveis estudadas, as que permaneceram associadas à mamada insatisfatória após análise multivariada foram comportamento do bebê na mamada, para o tipo barracudas, hiperexcitados e gulosos ( $O R=7,08$; IC $=3,30-15,05)$ e sucção débil ( $O R=7,70 ;$ IC $=3,66-16,16)$. O comportamento dos bebês na alimentação foi descrito inicialmente por Barnes et al. ${ }^{31}$, em 1953, que apontou cinco tipos diferentes: barracudas, excitados inefetivos, procrastinadores, gulosos e tranqüilos. O tipo barracudas mostra grande interesse na sucção e, assim, que colocado no peito, suga vigorosamente. Os "excitados inefetivos" são bebês muito excitados e hiperativos que não conseguem, no início, estabelecer um ritmo constante para a sucção. Já os bebês tipo "procrastinadores" adiam a sucção por até 45 dias após o parto e geralmente esperam a apojadura (descida do leite). Ao contrário dos barracudas, não mostram interesse particular nem habilidade na sucção nos primeiros dias. Os bebês "gulosos" insistem em degustar, saboreando um pouco de leite antes de mamar, cheirando e aproveitando o contato com o peito, tudo em ritmo lento.

O comportamento dos bebês deve ser considerado na avaliação da mamada, pois pode interferir no seu desempenho. Orientações específicas devem ser oferecidas para que cada mãe compreenda a singularidade de seu filho, facilitando o processo. Exemplificando, bebês mais agitados, como os "excitados inefetivos", precisam ser acolhidos e acalmados antes de serem colocados ao peito. Outros bebês, como os "gulosos", precisam de um período de tempo maior, antes de começarem a sugar, pois precisam estimular todos os sentidos. Isso traduz um início de interação importante, que exige intimidade entre mãe e filho $12,29,31,32$.

Widström \& Thingström-Paulsson ${ }^{33}$ salientam a necessidade de se respeitar a organização global, oral e o comportamento do bebê para que este responda adequadamente, utilizando da melhor maneira os reflexos de procura e sucção na amamentação. Em estudo realizado com 11 RN saudáveis, nascidos a termo de parto vaginal, com o objetivo de detectar a posição da língua na cavidade oral durante a estimulação dos reflexos orais antes da primeira sucção do RN, diagnosticou-se inadequação quando o bebê permanecia chorando. Quando os bebês são forçados a mamar sem que tenham demonstrado sinais de fome, geralmente respondem com choro e a língua se levanta, podendo dificultar a pega.

\section{Disfunções orais}

De um modo geral, vários fatores podem causar alterações na sucção do bebê na mamada, tais como intercorrências clínicas, baixo peso ao nascer (em especial prematuridade), distúrbios metabólicos, alterações neurológicas, síndromes e anomalias congênitas (fissuras labiopalatais, fissuras submucosas, anquiloglossia e laringomalacia). Algumas práticas clínicas relacionadas ao tratamento de bebês prematuros, como, por exemplo, intubação prolongada e uso sondas oro- ou nasogástricas também podem interferir no desenvolvimento normal da coordenação sucção/deglutição/respiração, bem como ocasionar problemas respiratórios, devido ao refluxo gastresofágico e aspiração 1,2,11-14,25,34.

Além dos fatores já mencionados, podem ocorrer transtornos de sucção mais específicos em bebês a termo, saudáveis e sem intercorrências clínicas, denominados disfunções motoras-orais. Estas são conseqüência de imaturidade neurológica do RN, dor facial (como a decorrente do uso de fórceps), características anatômicas individuais e fatores iatrogênicos, como o uso de bicos artificiais ${ }^{1,2,5,35,36}$. Logo após o nascimento, alguns RN apresentam incoordenação dos reflexos orais, necessitando de alguns dias para desenvolver um padrão mais maduro, o que pode ocorrer simultaneamente ao processo de apojadura, no terceiro ou quarto dia pós-parto. Podem ocorrer, ainda, alterações de natureza anatômica no funcionamento oral tanto do bebê (palato mais alto, mandíbula mais retraída ou freio lingual encurtado ou totalmente fixo - anquiloglossia -, apresentando, assim, maior dificuldade de pega) como da mãe (mamilos pouco elásticos, planos, invertidos ou excessivamente longos). Nesses casos, torna-se necessário intervir para auxiliar os bebês a realizarem adequadamente a pega e a extração de leite da mama de suas mães $3,5,36$.

Outro fator que pode gerar disfunção oral é o fenômeno denominado "confusão de bicos", devido ao contato precoce do neonato com bicos artificiais, sejam de mamadeira, chupeta ou protetores de mamilos em geral. Devido à habilidade limitada do neonato de adaptar-se a diversas configurações orais, pode surgir essa alteração, que, se persistente, poderá acarretar desmame precoce ${ }^{3}$. 
Observa-se, na prática clínica, que os RN que apresentam disfunções orais requerem muita habilidade e aprendizagem para ordenhar o peito de suas mães. Esses bebês podem necessitar de manobras não usuais e exercícios orofaciais, além de acompanhamento por um especialista consultor em aleitamento materno, com bastante experiência prática, ou fonoaudiólogo atuante em neonatologia, em programas de aleitamento materno. Freqüentemente, esses exercícios são conhecidos como "treino de sucção"12,35,36.

Righard et al. ${ }^{26}$, avaliando a técnica de amamentação na primeira semana de vida, demonstraram que a técnica correta de sucção tem forte influência sobre a duração do aleitamento materno. Os autores estudaram 82 pares mãe/ RN na Suécia com técnica inadequada de sucção (exclusiva do mamilo), dividindo a população em dois grupos, um no qual a sucção foi corrigida e outro no qual não foi, comparando-se posteriormente os resultados de ambos quanto ao aleitamento materno. Os autores constataram que a probabilidade de desmame precoce e de introdução da mamadeira no primeiro mês de vida foi 10 vezes maior no grupo de sucção não corrigida. Observou-se que as taxas de amamentação exclusiva e parcial foram mais elevadas no grupo que teve a sucção corrigida.

Andrade \& Gulo ${ }^{4}$, ao observar 30 mães e seus RN a termo, sem intercorrências clínicas ou malformações que dificultassem o aleitamento materno, verificaram associação entre padrão oral alterado e fissura mamilar. Apontaram como principais alterações orais a inadequação dos lábios e músculos orbiculares orais (ao redor dos lábios), que não permitiam a preensão adequada do mamilo, e também os movimentos de "mastigação do mamilo" durante a sucção em vez de movimentos de anteriorização e elevação, sendo esta apontada como a principal causa de traumas do mamilo.

No estudo de Sanches 27 , já descrito anteriormente, entre os 409 RN a termo, saudáveis, avaliados nas primeiras 24-48 horas, 134 (33\%) apresentaram mamada insatisfatória, sendo 71 casos ( $17 \%$ do total da amostra) relacionados à forma incorreta do $\mathrm{RN}$ de abocanhar a aréola. Desses, 43 tinham tensão labial excessiva, e 20, tensão diminuída. Em relação à ordenha da mama, foi diagnosticada mamada insatisfatória em 95 bebês (23\% do total da amostra) devido a movimentos mandibulares de "mastigação do mamilo - padrão mordedor" (91 casos), alteração do ritmo de ordenha, com ritmo muito rápido ou muito lento (59 casos), e ausência de ritmo estabelecido ( 29 casos). Observou-se, ainda, em relação à ordenha, 69 casos ( $17 \%$ do total da amostra) com movimentos inadequados da língua (língua pouco posteriorizada e sem canolamento durante a ordenha) e 14 casos ( $3 \%$ ) com língua totalmente posteriorizada.

\section{Manejo clínico da amamentação na vigência de disfunções orais}

As experiências que ocorrem nas primeiras mamadas rapidamente se tornam padrões bem definidos e tendem a se repetir, tanto para mãe quanto para o bebê, ${ }^{54}$. Se houver alguma disfunção, esta deverá ser corrigida precocemente, mediante avaliação motora oral do RN, já que é possível modificar a dinâmica de sucção. Estima-se que 5 a $6 \%$ dos bebês a termo, eutróficos e sem intercorrências clínicas apresentam disfunções orais e necessitam de manobras especiais para obter sucesso na amamentação 27,35 .

Na presença de disfunção oral, é indispensável uma anamnese específica que aborde história da mãe, gravidez, condições de nascimento, condições de lactação e da amamentação atual e prévias. Outros aspectos, além de observação da sucção não-nutritiva e avaliação detalhada da mamada, incluem número de sucções por pausa e força de sucção. Aspectos como interação mãe/filho e comportamento do RN devem ser incluídos tanto na observação como na atuação, devido à relação destes com a amamentação $12,22,26,27,35$.

Para a observação da sucção não-nutritiva, o examinador deve introduzir o dedo mínimo enluvado na boca do RN, para facilitar a percepção dos movimentos da língua. Pressiona-se o palato duro contra com a polpa do dedo (unha para baixo), de forma a estimular o reflexo de sucção. Em resposta, na sucção vigorosa e adequada, a língua deve envolver o dedo, ultrapassando a gengiva inferior, executando um movimento ondulatório, da ponta para a base, sendo que a ponta permanece projetada na parte anterior da boca. Os lábios devem estar relaxados e permanecer abertos, sem tensão1,2,35.

$\mathrm{Na}$ literatura especializada, são poucos os trabalhos científicos que referem condutas específicas para o acerto das disfunções orais na amamentação. A maioria se refere a problemas de manejo clínico do aleitamento materno como um todo, com correções do posicionamento e pega, já que, em geral, os casos de bebês a termo, saudáveis, com pega inadequada estão relacionados a erro de posição mãe/ bebê e, desta forma, obtém-se melhora com o manejo clínico básico da amamentação5,15,27,36.

No manejo clínico das disfunções orais, recorre-se com freqüência ao treino oral da sucção, que consiste na estimulação do reflexo de sucção, repetidamente, de modo sincrônico com o ritmo do bebê, conforme descrito na técnica de sucção não-nutritiva 1,35 . Todos os exercícios que envolvem estimulação oral devem ser realizados sempre antes da mamada, aproveitando-se a prontidão e a fome do bebê. Cuidados na aplicação dos exercícios orofaciais referem-se ao tipo e grau de gravidade das alterações orais, estado de consciência e comportamento global do bebê, relação e vínculo com os pais, tempo e uso dos exercícios e condições para retorno e seguimento, se necessário 9,34,36,37. Deve-se atuar com o bebê em estado de alerta ${ }^{32}$, de forma organizada, e sugere-se utilizar aproximadamente 2 a 5 minutos para estimulação, não ultrapassando esse tempo para não correr o risco de cansar e gerar estresse no bebê.

A Tabela 1 apresenta manobras e exercícios orofaciais empregados em disfunções orais simples, freqüentemente encontradas na prática clínica1,2,33,36,38-41. 
É importante ressaltar que as técnicas descritas na Tabela 1 são ilustrativas e sintéticas, referentes aos inúmeros transtornos orais que podem ocorrer no processo da amamentação. Portanto, as técnicas devem ser utilizadas como mais um instrumento no manejo clínico das disfunções orais, não devendo ser consideradas como um fim para a resolução de todos os problemas da amamentação.

Originalmente, muitos dos exercícios apresentados na Tabela 1 foram desenvolvidos para estimulação oral de bebês prematuros e/ou neurologicamente comprometi$\operatorname{dos}^{9,34,40,41}$. Eles sofreram adaptações para o emprego em bebês a termo e saudáveis, mas é necessário ter cautela na sua utilização, além de conhecimento e prática por parte de profissionais experientes no manejo clínico do aleitamento materno, a fim de se tornarem funcionais para bebês com dificuldades na amamentação.
Da mesma forma, a técnica denominada de finger feeding, também originalmente utilizada em RN prematuros e/ou neurologicamente comprometidos, atualmente é referida no auxílio de bebês com dificuldades de sucção, para um funcionamento oral mais efetivo. Essa técnica consiste na introdução do dedo enluvado na boca do bebê, no qual é acoplada uma sonda por onde flui o leite durante o treino da sucção ${ }^{35,39}$. A outra extremidade da sonda é colocada em um recipiente com leite materno ordenhado, leite de banco de leite ou fórmula láctea, de maneira que o bebê recebe esse leite ao sugar a mama. Marmet \& Shell 39 salientam, porém, que se essa técnica for realizada inadequadamente, poderá reforçar comportamentos não produtivos para a amamentação. As autoras sugerem treinar a abertura da boca do RN anteriormente à utilização dessa técnica e manutenção da amamentação, para que o bebê não reforce padrões inadequados e desista do peito.

Tabela 1 - Manejo clínico das disfunções orais

Tipo de disfunção oral Descrição do padrão oral inadequado Intervenção para mãe/bebê

Reflexo de procura e sucção débeis

Lábios invertidos

Padrão mordedor

Tensão oral excessiva

Língua posteriorizada

Língua hipertônica, em posição alta na cavidade oral
Antes da mamada, os reflexos mostram-se pouco ativos, irregulares, com força diminuída.

Os lábios, principalmente o inferior, permanecem voltados para dentro, mesmo após a resposta do reflexo de procura, quando o bebê abocanha o peito.

Ocorre quando a mandíbula realiza movimentos repetitivos de cima para baixo, causando abertura e fechamento da boca, podendo levar ao contato traumático das gengivas contra o mamilo.

A musculatura perioral apresenta um aumento do tônus, dificultando a abertura correta da boca, bem como a manutenção dessa abertura.

Língua permanece na porção posterior da cavidade oral durante a sucção.

A língua permanece alta na cavidade oral quando o peito é introduzido, formando uma barreira contra o peito.
Inicialmente, estimular suavemente o reflexo de procura, tocando os lábios do bebê, principalmente o inferior, e as bochechas. Mediante a resposta de procura do bebê, estimular o reflexo de sucção, três a quatro vezes, antes da mamada. Em paralelo, esvaziar um pouco a mama e colocar o bebê no peito quando o reflexo de ejeção do leite já estiver ativado. Repetir a operação várias vezes, até que a sucção se fortaleça.

Manobra de facilitação labial:

- se a pega ocorrer no local correto, puxar delicadamente os lábios para fora. Se o bebê estiver mamando apenas no mamilo, é preciso reposicioná-lo e, então, acertar os lábios;

- se o padrão inadequado persistir, manter a manobra labial durante toda a mamada, até que o bebê consiga fazê-lo sozinho.

Manobra de facilitação:

- inicialmente, estimular o reflexo de procura do bebê várias vezes e facilitar o encaixe adequado ao peito;

- durante a mamada, dar contenção à mandíbula, apoiando-a delicadamente, com o dedo indicador ou médio, reforçando a abertura da boca do bebê, de modo que este projete a língua na sucção.

Estimular várias vezes o reflexo de procura do bebê antes de colocá-lo no peito, até observar que este realiza uma abertura ampla da boca e a musculatura perioral ceder à tensão excessiva. Só então permitir que o bebê faça a pega corretamente. Se o padrão inadequado persistir, realizar a manobra citada no padrão mordedor.

Utilizar a técnica do treino oral da sucção, puxando gentilmente a língua para a frente.

Delicadamente, introduzir o dedo mínimo enluvado na boca do bebê e abaixar a língua algumas vezes.

Em seguida, utilizar a técnica do treino da sucção. 
A participação dos pais como agentes ativos do processo é fundamental, observando e favorecendo as modificações, uma vez que essas intervenções são realizadas no ambiente familiar até a adequação completa do funcionamento oral na amamentação 2,36,39.

A correção das disfunções orais pode ser fácil e ocorrer em poucos dias, desde que os exercícios ou manobras sejam aplicados de modo contínuo e a mãe ou familiares sejam bem orientados. Nos casos mais persistentes, pode durar até semanas, e torna-se necessário atendimento especializado ${ }^{34}$ (fonoaudiológico com atuação em neonatologia e experiência em aleitamento materno ou especialista em aleitamento materno), que se baseia na estimulação oral individualizada, envolvendo seqüência de exercícios, incluindo manobras e ajustes, além de exercícios orofaciais variados. É necessário rígido controle do tempo e da quantidade de estímulos, mediante a observação criteriosa das respostas e do comportamento do bebê 34,36 . Exercícios orofaciais utilizados indiscriminadamente podem agravar as disfunções orais, gerando ainda mais desorganização no funcionamento oral dos bebês. Além disso, o uso de tais exercícios em bebês intactos neurologicamente tem sido controverso entre terapeutas, pois eles podem ser muito fortes para o sistema neuromuscular do bebê a termo ${ }^{35}$. É imprescindível realizar quantos retornos forem necessários, mantendo o seguimento das duplas mães/bebês e acompanhando o desenvolvimento da amamentação 2,34,36,39.

No caso da anquiloglossia, a indicação para frenectomia é controversa e depende da resposta funcional da língua nos movimentos para ordenha durante a mamada. Ballard et al. ${ }^{42}$, pesquisando a anquiloglossia e sua repercussão na amamentação, acompanharam 2.763 bebês a termo em aleitamento materno internados no Cincinnati Children's Hospital Medical Center, Estados Unidos, e 273 em seguimento ambulatorial com problemas na mamada por possíveis problemas decorrentes de anquiloglossia. Cada bebê foi observado durante a amamentação e avaliado com protocolo especial (Hazelbaker Assessment Tool for Lingual Frenulum Function), que consiste em um método quantitativo para medir a função da língua e a aparência, facilitando a identificação de bebês com grau importante de anquiloglossia. Do total de 3.036 bebês em aleitamento materno, foram identificados 88 casos (3,2\%) entre os RN internados e $35(12,8 \%)$ entre os provenientes do ambulatório. Anquiloglossia importante foi responsável por problemas sérios na amamentação dos pacientes em seguimento ambulatorial. Após criteriosa avaliação da função da língua, na presença de anquiloglossia significativa a frenectomia mostrou ser um facilitador para a amamentação nos 123 casos com indicação cirúrgica. Conseqüentemente, observou-se melhora no padrão de transferência de leite, bem como no que diz respeito a problemas do mamilo da mãe e patologias da mama.

\section{Considerações finais}

As disfunções orais podem ser identificadas precocemente mediante anamnese dirigida, avaliação oral do RN e observação minuciosa da mamada. Esses procedimentos devem fazer parte do serviço das maternidades, e, para isso, sugere-se treinamento constante dos profissionais (obrigatórios nos hospitais credenciados como Amigo da Criança - OMS/UNICEF) para a realização da avaliação da mamada e atuação da equipe interdisciplinar, incluindo fonoaudiólogo sempre que possível na rotina nas maternidades.

Para o manejo adequado das disfunções orais, faz-se necessário conhecimento sobre anatomia e neurofisiologia oral do RN, bem como experiência no manejo clínico da amamentação. Casos mais complexos e persistentes requerem diagnóstico e seguimento com especialistas, que pode ser fonoaudiólogo com prática em aleitamento materno ou especialista em amamentação.

\section{Agradecimentos}

À Maria Lúcia de Faria Ferraz, bibliotecária da Faculdade de Saúde Pública/USP, pelo apoio e preciosa contribuição na extensa revisão da literatura.

\section{Referências}

1. Váldes V, Sanchez AP, Labbok M. Técnicas de amamentação. In: Váldes V, Sanchez AP, Labbok M, editores. Manejo clínico da amamentação. Rio de Janeiro: Revinter; 1996.p. 48-54.

2. Sanches MTC. Amamentação-Enfoque fonoaudiológico. In: Carvalho RT, Tamez RN, editores. Amamentação-bases científicas para prática profissiona. $1^{\text {a }}$ ed. Rio de Janeiro: Guanabara Koogan S.A.; 2002. p. 50-59.

3. Neifert M, Lawrence R, Seacat J. Nipple confusion: toward a formal definition. J Pediatr. 1995;126:125-9.

4. Andrade CF, Gullo AC. As alterações do sistema motor oral dos bebês como causa das fissuras/rachaduras mamilares. Pediatria São Paulo. 1993;15:28-33.

5. Escott R. Positioning, attachment and milk transfer. Breastfeeding Review 1989;5:31-7.

6. Crelin E. cavidade oral e língua. In: Crelin E, editor. Anatomia do recém-nascido. São Paulo: Panamericana; 1988. p. 27-30.

7. Douglas CR. Conceitos gerais sobre fisiologia bucal. In: Douglas $C R$, editor. Tratado de fisiologia aplicada às ciências da saúde. São Paulo: Robe Editorial; 1994. p. 827-910.

8. Segovia ML. Maduración de las praxias estomatológicas. In: Segovia ML. Interrelaciones entre la odontoestomatologia y la fonoaudiologia - la deglución atípica. $2^{a}$ ed. Buenos Aires: Panamericana; 1988. p. 67-82.

9. Morris SE, Klein MD. Pré-feeding skills: a comprehensive resource for feeding development. Arizona: Communication Skill Builders; 1987.

10. Naylor JA. Development of oral function. In Developmental readiness of normal full term infants to progress from exclusive breastfeeding to introduction of complementary foods. Wellstart International in collaboration with Linkages: breastfeeding; 2001.

11. King FS. Como ajudar as mães a amamentar. Londrina: Universidade Estadual de Londrina; 1991.

12. Lawrence RA. Breastfeeding: A guide for the medical profession. 4th ed. Saint Louis: Mosby; 1994.

13. Bu'Lock F, Woolridge MW, Baum JD. Development of coordination of sucking, swallowing and breathing: ultrasound study of term and preterm infants. Dev Med Child Neurol. 1990;32:669-78.

14. Weber F, Woolridge MW, Baum JD. An ultrasonographic study of the organization of sucking and swallowing by newborn infants. Dev Med Child Neurol. 1986;28:9-24.

15. Woolridge MW. Aetiology of sore nipples. Midwifery. 1986;2: 172-6. 
16. Woolridge MW. The anatomy of infant sucking. Midwifery. $1986 ; 2: 164-71$.

17. Carvalho GD. Amamentação e o sistema estomatognático. In: Carvalho RT, Tamez RN, eds. Amamentação-bases científicas para prática profissiona. Rio de Janeiro: Revinter; 2002. p. 37-49.

18. OMS/UNICEF. Organização Mundial de Saúde. Aconselhamento em amamentação: um curso de treinamento. São Paulo: Instituto de Saúde/OMS/OPAS; 1995.

19. Rea MF. Reflexões sobre a amamentação no Brasil: de como passamos a 10 meses de duração. Cad Saúde Publ. 2003; 19:109-18.

20. Toma TS. Iniciativa Hospital Amigo da Criança: diagnóstico das práticas de alimentação infantil em maternidades públicas e privadas do município de São Paulo [dissertação]. São Paulo: Universidade de São Paulo; 2000.

21. Venancio SI. Dificuldades para o estabelecimento da amamentação: o papel das práticas assistenciais das maternidades. J Pediatr (Rio J). 2003;79:1-2.

22. Carvalhaes $M A B L$, Correa $C R H$. Identificação de dificuldades no início do aleitamento materno mediante aplicação de protocolo. J Pediatr (Rio J). 2003;79:13-20.

23. Vinha VP, Pelá NT, Shimo AK, Scochi CG. Trauma mamilar: proposta de tratamento. Femina. 1987;15:370-8.

24. Motter A, Ferreira CA, Schaffer G, Wengerkiewicz JC, Rosa LC. Prevenção de fissura de mamilo e estímulo à amamentação. Fisioterapia em movimento 1992;5:61-70.

25. Murahovschi J, Teruya KM, Bueno LGS, Baldin PE. Amamentaçao. Da teoria à prática. Manual para profissionais de saúde. $2^{a}$ ed. Santos: Fundação Lusíadas/Centro de Lactação/OPAS/INAM/ INST. DE SAÚDE; 1998.

26. Righard L, Alade MO. Sucking technique and its effect on success of breastfeeding. Birth 1992;19:185-9.

27. Sanches MTC. Dificuldades iniciais na amamentação - Enfoque fonoaudiológico [dissertação]. São Paulo: Universidade de São Paulo; 2000.

28. Giugliani ERJ. O Aleitamento Materno na Prática Clínica. J Pediatr (Rio J). 2000;76(Supl 3):S238-252.

29. Winnicott DW. Os bebês e suas mães. $3^{a}$ ed. São Paulo: Martins Fontes; 1996.

30. Nascimento LFC. Amamentação: influência de alguns fatores dos períodos pré-natal e perinatal. Pediatria Moderna. 2002;38:507-12

31. Barnes GR, Lethin Jr AN, Jackson EB, Shea N. Management of breastfeeding. JAMA. 1953;151:192-9.
32. Brazelton TB. O desenvolvimento do apego: uma família em formação. Porto Alegre: Artes Médicas; 1988.

33. Widström AM, Thingström-Paulsson J. The position of the tongue during rooting reflexes elicited in newborn infants before the first suckle. Acta Paediatr. 1993;82:281-3.

34. Marmet $C$, Shell E. Training neonates to suck correctly. J Matern Child Health. 1984;9:401-7.

35. Bovey A, Noble R, Noble M. Orofacial exercises for babies with breastfeeding problems? Breastfeeding Rewiew. 1999;7:23-8.

36. Glass RP, Wolf LS. A global perspective on feeding assessment in the neonatal intensive care unit. Am J Occup Thy. 1994;48:514-26.

37. Als H. A synactive model of neonatal behavior organization: framework for assessment of neurobehavioral development in the premature infant and for support of infants and parents in the neonatal intensive care environment. Phys Occup Thy Pediatr. 1986;6:3-53.

38. Sanches MTC. Intervenção fonoaudiológica no aleitamento materno. Abstracts do II Congresso Goiano de Odontopediatria e II Encontro Goiano de Promoção de Saúde. Goiânia, 1997 Nov 13-15; Goiás, Brasil. Goiânia: Associação Goiana de Odontopediatria; 1997. p. 64-6.

39. Marmet $C$, Shell E. Assessing infant suck dysfunction: case management. J Hum Lact. 2000;16:332-6.

40. Lang S. Posicionamento e fixação do lactente ao seio. In: Lang S, editor. Aleitamento do lactente, cuidados especiais. São Paulo: Livraria Editora Santos; 1999. p. 21-42.

41. Fucile S, Gisel E, Lau C. Oral stimulation accelerates the transition from tube to oral feeding in preterm infants. J Pediatr. 2002:141:230-6.

42. Ballard JL, Auer CE, Khoury JC. Ankyloglossia: assessment, incidence, and effect of frenuloplasty on the breastfeeding dyad. Pediatrics. 2002 Nov;110(5):e63.

Correspondência:

Maria Teresa Cera Sanches

Instituto de Saúde, NISMC

Rua Santo Antônio, 590, $2^{\circ}$ andar

CEP 01314-000 - São Paulo, SP

Fone/Fax: (11) 3293.2232

E-mail: mtsanches@isaude.sp.gov.br ou mtesan@uol.com.br 